\title{
The Value of Multilateral Trade Liberalization and the Need for Third-Party Sanction
}

\author{
by \\ Kong-Pin Chen ${ }^{a}$ Cheng-Zhong Qin ${ }^{b}$ and Larry D Qiu ${ }^{c *}$
}

January 2002

\begin{abstract}
Trade policies such as tariffs are often featured by the prisoner's dilemma. One country's trade liberalization is vulnerable to the opportunism of another country. This problem is more serious in cases where a country behaving opportunistically can only be punished by the victims. In a trade model with three countries, we show that "circular concessions" are the only way to have any Pareto-improving trade liberalization. The circular nature of the concessions implies that if punishment can be carried out only by the victim of opportunistic behavior, multilateral trade liberalization cannot be sustained. Our results have implications for rule design in multilateral trade systems such as the WTO.

JEL Classification No.: F12, F13

Key Words: multilateral trade liberalization, WTO

${ }^{a}$ Institute for Social Sciences and Philosophy, Academia Sinica, Taipei, Taiwan.

${ }^{b}$ University of California, Santa Barbara, CA 93106.

${ }^{c}$ Hong Kong University of Science and Technology, Kowloon, Hong Kong.

* Corresponding author: Larry D. Qiu, Department of Economics, Hong Kong University of Science and Technology, Kowloon, Hong Kong, tel: (852)2358-7628, fax: (852)23582084, email: larryqiu@ust.hk.
\end{abstract}

We benefitted from comments by Stephen Ching and participants at the International Conference on Greater China and the WTO, held in March 2001 in Hong Kong. 


\section{Introduction}

The GATT/WTO and preferential trade agreements help member countries to achieve further gains from trade by promoting deeper trade liberalization. In general, free trade does not automatically follow from individualistic behavior. A major reason for this has to do with the existence of monopolistic power in trade. ${ }^{1}$ Trade liberalization requires that countries behave cooperatively and reciprocally. In certain circumstances, greater cooperation and reciprocity can only be achieved through multilateral trade agreements, as opposed to a web of bilateral trade agreements, ${ }^{2}$ and sustained through third-party punishments.

To illustrate, consider three countries: China, Japan, and the United States. The US would be better off if Japan would open its market to US agricultural products. However, in this case, the US has few sectors with which to reciprocate because almost all US markets are already very open to Japanese products. The lack of reciprocity discourages Japan and the US from reaching a bilateral agreement for further trade liberalizations. On the other hand, China can reduce its tariffs on electrical appliances that would help Japan since Japan is a major exporter of these goods in the world, but Japan has few sectors with which to reciprocate. To induce China to reduce tariffs on electrical appliances, the US can phase out its Multifiber Arrangement, which sets export quotas on textile products from China and some other countries, so that China can export more textiles and clothing

\footnotetext{
${ }^{1}$ As shown by Harry Johnson (1953-54), the optimal tariff for an individual country is generally not zero. Other important arguments for protection include the protection of infant industries and the political economy of trade policies.

${ }^{2}$ Multilateralism is not unanimously preferred to bilateralism. For example, Deardorff and Stern (1997) argue that it is more difficult for many countries to reach consensus on trade issues, as compared when two countries are involved. Other examples along this line include Krugman (1991), Bhagwati and Panagariya (1996), Bagwell and Staiger (1999) and Maggi (1999).
} 
to the US. As a result, circular concessions may occur and, based on such concessions, a multilateral trade liberalization in three sectors would benefit all three countries.

The above illustration demonstrates an important advantage of multilateral trade agreements over bilateral ones. Such an advantage is created from bilateral imbalances of power, in the sense that one country can make more tariff concessions to another country but not conversely. Thus the former is "more powerful" because it stands to lose less from a bilateral trade war. As shown by Maggi (1999), in the presence of bilateral imbalances of power, outcomes that are Pareto superior to the ones that are sustainable with bilateral trade agreements can be achieved with multilateral trade agreements and third-party punishment. The reason is simple. With bilateral agreements for deeper trade liberalization, the victim (the less powerful one) is not able to punish the defector (the more powerful one) sufficiently strongly to deter defection. However, with a multilateral trade agreement combined with third-party punishment, the joint punishment would be stronger and so deeper liberalization can be sustained. In the present paper, we explore circumstances in which any Pareto improvement upon the "unilateral subgame-perfect equilibrium" 3 must be supported by a multilateral trade agreement together with third-party punishment. As in Maggi (1999), this paper provides a rationale for joint punishment by both the victims and nonvictims of defection. However, our paper tries to extend Maggi's (1999) work in several directions as discussed below.

We consider a three-country trade model that is shown to exhibit triangular trade, where a country is a net exporter to another country that in turn is a net exporter to a

\footnotetext{
${ }^{3}$ The subgame-perfect equilibrium of a two-stage game, in which the countries set their tariffs independently in the first stage and while observing these tariffs, the firms decide on their quantities independently in the second stage (see the next section). As in Maggi (1999), the word "unilateral" is used to emphasize the fact that multilateral trade agreements are not yet considered.
} 
third country, and this third country in turn is a net exporter to the first one. ${ }^{4}$ In Maggi (1999), certain welfare improvements upon the unilateral Nash equilibrium ${ }^{5}$ are possible via bilateral trade agreements that do not involve any thirty-party punishment. That is, only more significant improvements require multilateral trade agreements with thirtyparty punishment. We show, in the present paper, that there are situations in which any welfare improvement from the unilateral subgame-perfect equilibrium, small or large, requires a multilateral agreement with third-party punishment. This result is significant as we observe that most multilateral trade liberalizations take place in a gradual fashion. ${ }^{6}$ Thus, our result implies that in certain circumstances third-party punishment may be required even when trade liberalization takes place gradually.

In Maggi (1999), endowments are assigned to the trading countries and so supply is not affected in any way by changes in trade policies. As a result, strategic reactions by firms to changes in a country's trade policies cannot be examined in such a model. Given the trade policies of all three countries, the first welfare theorem of the general equilibrium theory implies that gains from trade are exhausted by the resulting worldwide competitive equilibrium. Gains from defecting by any country tend to be small under these assumptions. One therefore wonders whether bilateral imbalances of power become stronger or weaker without these assumptions. In the present paper, we relax these assumptions and show that bilateral imbalances of power are not as extreme as they

\footnotetext{
${ }^{4}$ Krugman and Obstfeld (2000, p. 236) point out that some advantageous trade deals inherently involve more than two countries since such bilateral imbalances of power link them together. In particular, they mention the following situation: "The United States sells more to Europe, Europe sells more to Saudi Arabia, Saudi Arabia sells more to Japan, and Japan sells more to the United States."

${ }^{5}$ In Maggi (1999), only the countries behave strategically in deciding the tariffs. Both firms and consumers are competitive. Hence, the model there is basically a one-stage game

${ }^{6}$ For a survey of studies on gradual trade liberalization, see Staiger (1995).
} 
appear to be. Hence, to realize greater gains from trade, punishment by nonvictims or third-parties should not be entirely ruled out.

There are two interesting points associated with the above-mentioned results. First, although it is generally true that collective punishment helps support Pareto-improving multilateral trade liberalizations, we show that there are situations in which the resulting trade patterns make third-party punishment necessary to sustain any Pareto-improving multilateral trade liberalization from the unilateral subgame-perfect equilibrium. Second, with respect to the rules and procedures governing the settlement of disputes, the WTO is clearly mute on the possibility of allowing nonvictim member countries to punish a defector. ${ }^{7}$ An implication is that more explicit rules regarding third-party punishment may be needed in order to facilitate deeper trade liberalization in some cases.

The rest of the paper is organized as follows. In Section 2, we develop the model and analyze the value of multilateral trade liberalization. In Section 3, we examine the need for third-party punishment. Concluding remarks are in Section 4.

\section{Pareto-Improving Multilateral Trade Liberalization}

Consider a world in which there are three countries and three goods. We call both the countries and the goods 1,2 , and 3 . Unless otherwise specified, we distinguish the two sets of names with using a superscript for countries and a subscript for goods. Each country produces two goods but consumes all three of them. Country $i$ produces goods $i$ and $i+1$, for $i=1,2$, and 3 . When $i+j>3$, it will be understood that $i+j$ are modularized by 3 . Hence, good $i$ is produced by country $i$ and country $i+2$ (see Figure

\footnotetext{
${ }^{7}$ Maggi (1999) argues that nonvictim members of the WTO can punish the defecting government in some subtle ways by withdrawing some of their "goodwill" toward that government. However, this is not included as part of the WTO rules.
} 
1 for an illustration).

Country $i$ 's production technologies have constant marginal costs, which are denoted by $c_{i}^{i}$ and $c_{i+1}^{i}$, respectively. Country $i$ 's demand for good $j$ is $P_{j}^{i}\left(Q_{j}\right)=a_{j}^{i}-Q_{j}$, for $j=1,2,3$. Finally, there is in each country at most one firm producing each good.

\subsection{The Unilateral Subgame-Perfect Equilibrium}

As the purpose of this paper is to demonstrate an advantage of multilateral trade liberalizations (over bilateral ones) and the necessity of third-party punishment, we focus on a particular trade pattern resulting from the following assumptions on the cost and demand functions:

- $A 1: c_{i}^{i+2}>a_{i}^{i}>c_{i}^{i}$,

- $A 2: a_{i+1}^{i}>\max \left\{c_{i+1}^{i}, c_{i+1}^{i+1}\right\}$,

- $A 3: a_{i+2}^{i}>\max \left\{c_{i+2}^{i+1}, c_{i+2}^{i+2}\right\}$.

$A 1$ implies that country $i$ will produce good $i$ but will not import it, because the other producer of the good (i.e., country $i+2$ ) has a cost of production which is too high relative to the market demand for the good in country $i$. Under $A 2$, country $i$ will produce good $i+1$ and will also import it from country $i+1$. Finally, $A 3$ implies that country $i$ 's market demand for good $i+2$, which country $i$ does not produce, is strong enough that it imports the good from both countries $i+1$ and $i+2$. Figure 1 depicts the trade flows for country 1, where the arrows indicate the directions of trade.

\section{Figure 1: The Pattern of Trade}

Given the above specifications of the cost and demand functions and hence the above pattern of trade, we can assume, without loss of generality, that country i only considers 
a tuple, $t^{i}=\left\{t_{i+1}^{i}, t_{(i+1)(i+2)}^{i}, t_{(i+2)(i+2)}^{i}\right\}$, of three tariffs, where $t_{i+1}^{i}$ denotes country $i$ 's tariff on good $i+1$ (imported from country $i+1$ ) and $t_{j(i+2)}^{i}$ is country $i$ 's tariff ${ }^{8}$ on good $i+2$ imported from country $j$ for $j=i+1, i+2$. Let $t=\left\{t^{1}, t^{2}, t^{3}\right\}$ be the collection of all tariffs in the world.

We consider a two-stage model: Tariffs are set by the countries in the first stage and the firms observing the tariffs worldwide decide on their quantities in the second stage. We solve for a subgame-perfect equilibrium by working backwards. Due to political considerations, we assume that country i chooses its tariffs, $t^{i}$, to maximize the following weighted welfare function

$$
W^{i}(t)=\sum_{h=i}^{i+1} \sum_{j=1}^{3} \Pi_{j h}^{i}(t)+\lambda_{i} \sum_{h=1}^{3} C S_{h}^{i}(t)+\sum_{h=1}^{3} T R_{h}^{i}(t)
$$

where $\Pi_{j h}^{i}(t)$ denotes country $i$ 's profit from selling good $h$ in country $j, C S_{h}^{i}(t)$ denotes country $i$ 's consumer surplus from good $h$, and $T R_{h}^{i}(t)$ denotes country $i$ 's tariff revenue from importing good $h$. They are all evaluated at the Nash equilibrium of the subgame played by the firms worldwide in the second stage led by the tariffs as embodied in $t .^{9}$ Parameter $\lambda_{i}>0$ denotes the welfare weight for the total consumer surplus of country $i$.

Note that the functional forms of the demand functions imply that the markets are not interrelated, in the sense that a change in the price of a good in one place does not affect demand for either of the other two goods in any place. Thus, given $t$, the second stage Nash equilibrium quantities of the firms without subjecting to the nonnegativity

\footnotetext{
${ }^{8}$ The Most Favored Nation clause of the GATT/WTO is not imposed at this point. That is, tariffs are set on a bilateral basis.

${ }^{9}$ The Nash equilibrium in each stage is unique under our specifications of the demand and cost functions.
} 
constraint are given by

$$
\begin{gathered}
\hat{q}_{i i}^{i}=\frac{a_{i}^{i}-2 c_{i}^{i}}{3}, \\
\hat{q}_{i(i+1)}^{i}=\frac{a_{i+1}^{i}-2 c_{i+1}^{i}+c_{i+1}^{i+1}+t_{i+1}^{i}}{3}, \quad \hat{q}_{i(i+1)}^{i+1}=\hat{q}_{i(i+1)}^{i}+c_{i+1}^{i}-c_{i+1}^{i+1}, \\
\hat{q}_{i(i+2)}^{i+1}=\frac{a_{i+2}^{i}-2 c_{i+2}^{i+1}-2 t_{(i+1)(i+2)}^{i}+c_{i+2}^{i+2}+t_{(i+2)(i+2)}^{i}}{3}, \quad \hat{q}_{i(i+2)}^{i+2}=\hat{q}_{i(i+1)}^{i+1}+c_{i+2}^{i+1}-c_{i+2}^{i+2},
\end{gathered}
$$

where $c_{i}^{\prime i+2}=c_{i}^{i+2}+t_{i+1}^{i}, c_{i+1}^{i+1}=c_{i+1}^{i+1}+t_{i+1}^{i}, c_{i+2}^{i+1}=c_{i+2}^{i+1}+t_{(i+1)(i+2)}^{i}, c_{i+2}^{i+2}=c_{i+2}^{i+2}+t_{(i+2)(i+2)}^{i}$, where $\hat{q}_{j k}^{i}$ denotes the quantity of good $k$ produced by country $i$ and sold in country $j$. Thus, by substituting (2)-(4) into the weighted welfare functions in (1), simple calculation shows that the subgame-perfect equilibrium tariffs without subjecting to the nonnegativity constraint are given by

$$
\begin{gathered}
\hat{t}_{i+1}^{i}=\frac{\left(5-2 \lambda_{i}\right) a_{i+1}^{i}+\left(\lambda_{i}-1\right) c_{i+1}^{i}+\left(\lambda_{i}-4\right) c_{i+1}^{i+1}}{10-\lambda_{i}}, \\
\hat{t}_{(i+1)(i+2)}^{i}=\frac{2\left(3-2 \lambda_{i}\right) a_{i+2}^{i}+\left(3 \lambda_{i}-6\right) c_{i+2}^{i+1}+\lambda_{i} c_{i+2}^{i+2}}{4\left(3-\lambda_{i}\right)}, \\
\hat{t}_{(i+2)(i+2)}^{i}=\frac{2\left(3-2 \lambda_{i}\right) a_{i+2}^{i}+\left(3 \lambda_{i}-6\right) c_{i+2}^{i+2}+\lambda_{i} c_{i+2}^{i+1}}{4\left(3-\lambda_{i}\right)} .
\end{gathered}
$$

When $1.5<\lambda_{i}<3, A 3$ and equations (6) and (7) imply $\hat{t}_{(i+1)(i+2)}^{i}<0$ and $\hat{t}_{(i+2)(i+2)}^{i}<$ 0 . When $\lambda_{i}<2.5, A 2$ and equation (5) imply that good $i+1$ will be produced in both country $i$ and country $i+1$ and it will also be imported by country $i$ from country $i+1$. Hence, as shown in Proposition 1 below, country i imposes a positive tariff only on good $i+1$ that it imports from country $i+1$ when $1.5<\lambda_{i}<2.5$. The unilateral subgame-perfect equilibrium refers to the subgame-perfect equilibrium of the above two-stage model with the quantities and the tariffs all subject to the nonnegativity constraint.

Proposition 1: Assume A1-A3 hold and $1.5<\lambda_{i}<2.5$. Assume that further negative 
quantities and tariffs are not feasible. Then $t_{(i+1)(i+2)}^{* i}=t_{(i+2)(i+2)}^{* i}=0$ and $t_{i+1}^{* i}>0$ in the unilateral subgame-perfect equilibrium.

Proof: Note first that the separability of the objective function implies that, in the unilateral subgame-perfect equilibrium, the tariff $t_{i+1}^{* i}$ is determined by maximizing $\Pi_{i(i+1)}^{i}(t)+$ $\lambda_{i} C S_{i+1}^{i}(t)+T R_{i+1}^{i}(t)$, subject to the nonnegativity constraint. By (5), $\hat{t}_{i+1}^{i}>0$ when $1.5<\lambda_{i}<2.5$. We thus have $t_{i+1}^{* i}>0$.

Observe next that $t_{(i+1)(i+2)}^{i}$ and $t_{(i+2)(i+2)}^{i}$ only appear in consumer surplus, $C S_{i+2}^{i}$, and tariff revenue, $T R_{i+2}^{i}$. Furthermore, both $C S_{i+2}^{i}$ and $T R_{i+2}^{i}$ are functions of only these two tariffs. Consequently, in the unilateral subgame-perfect equilibrium, the tariffs $t_{(i+1)(i+2)}^{* i}$ and $t_{(i+2)(i+2)}^{* i}$ are determined by maximizing $\lambda_{i} C S_{i+2}^{i}\left(t_{(i+1)(i+2)}^{i}, t_{(i+2)(i+2)}^{i}\right)+$ $T R_{i+2}^{i}\left(t_{(i+1)(i+2)}^{i}, t_{(i+2)(i+2)}^{i}\right)$, subject to the nonnegativity constraint. By (4), this sum is concave. ${ }^{10}$ Hence, it is also concave in any one of the two tariffs holding the other one constant. By (6) and (7), both $\hat{t}_{(i+1)(i+2)}^{i}$ and $\hat{t}_{(i+2)(i+2)}^{i}$ are negative when $1.5<\lambda_{i}<2.5$. Thus, by the concavity of $\lambda_{i} C S_{i+2}^{i}+T R_{i+2}^{i}, t_{(i+1)(i+2)}^{* i}=t_{(i+2)(i+2)}^{* i}=0 . \quad$ QED

Equations (5)-(7) imply that for free trade to be a unilateral subgame-perfect equilibrium outcome, we must have $a_{i+1}^{i}=c_{i+1}^{i}=c_{i+1}^{i+1}$ and $a_{i+2}^{i}=c_{i+2}^{i+1}=c_{i+2}^{i+2}$. These conditions in turn imply that country $i$ only produces good $i$ and there is no trade. What this shows is simply that in the static two-stage model, it is impossible to support free trade as a unilateral subgame-perfect equilibrium outcome.

\subsection{Pareto-Improving Trade Liberalization}

When $t_{(i+1)(i+2)}^{* i}=t_{(i+2)(i+2)}^{* i}=0$ and $t_{i+1}^{* i}>0$, which is the unilateral subgame-perfect

\footnotetext{
${ }^{10}$ Recall that in calculating subgame-perfect equilibrium, firms' quantities must be as in (2)(4), given any tariff collection t.
} 
equilibrium as shown in Proposition 1, we say that the three countries make "circular concessions". Building upon Proposition 1, we show in this section that any Paretoimproving trade liberalization agreement from the unilateral subgame-perfect equilibrium would require countries to make "circular concessions." This in turn implies that no Pareto-improving bilateral trade liberalization agreement is possible in the static twostage model.

Proposition 2: With the same assumptions as in Proposition 1, a Pareto improvement from the unilateral subgame-perfect equilibrium is possible through and only through a multilateral trade agreement that involves circular concessions in tariff reductions, such that country $i$ reduces its tariffs, $t_{i+1}^{* i}$, on good $i+1, i=1,2,3$.

Proof: From Proposition 1, the only possible trade liberalization from the unilateral subgame-perfect equilibrium in country $i$ is to reduce its tariff on good $i+1$, for $i=1,2,3$. Denote by $w^{i}(t)$ the part of country $i$ 's weighted welfare function that will be affected by such trade liberalization in all countries. Then ${ }^{11}$

$$
w^{i}(t)=\Pi_{(i+2) i}^{i}\left(t_{i}^{i+2}\right)+w_{i+1}^{i}\left(t_{i+1}^{i}\right)
$$

where $w_{i+1}^{i}\left(t_{i+1}^{i}\right)=\Pi_{i(i+1)}^{i}\left(t_{i+1}^{i}\right)+\lambda_{i} C S_{i+1}^{i}\left(t_{i+1}^{i}\right)+T R_{i+1}^{i}\left(t_{i+1}^{i}\right)$.

Let country $i$ reduce its tariff from $t_{i+1}^{* i}$ by an amount $\epsilon^{i}$ with $0<\epsilon^{i} \leqslant t_{i+1}^{* i}$. By (8), such a trade liberalization in country $i$ causes a reduction in country $i$ 's own welfare by the amount $\Delta w_{i+1}^{i}\left(\epsilon^{i}\right)=w_{i+1}^{i}\left(t_{i+1}^{* i}\right)-w_{i+1}^{i}\left(t_{i+1}^{* i}-\epsilon^{i}\right)^{12}$ and an increment in country

\footnotetext{
${ }^{11}$ As noticed before, linearity in cost and demand functions implies that country $i$ 's profit from selling good $i$ to country $i+2$ does not depend on tariff levels other than $t_{i}^{i+2}$. Similarly, a country's consumer surplus and tariff revenue associated with good $i+1$ do not depend on tariffs other than $t_{i+1}^{i}$.

${ }^{12}$ Since the tariff levels before trade liberalization agreements are taken to be those in the unilateral tariff Nash equilibrium, we can write such welfare changes simply as functions of the tariff reductions only.
} 
$i+1$ 's welfare by the amount $\Delta \prod_{i(i+1)}^{i+1}\left(\epsilon^{i}\right)=\prod_{i(i+1)}^{i+1}\left(t_{i+1}^{* i}-\epsilon^{i}\right)-\prod_{i(i+1)}^{i+1}\left(t_{i+1}^{* i}\right)$. Thus, country $i$ only gains from trade liberalization in country $i+2$ and it becomes better off only when this gain exceeds its loss resulting from its own trade liberalizations. This shows that Pareto-improving trade liberalizations must be all of the sort "country $i$ reduces its tariff on good $i+1$ imported from country $i+1$." Such trade liberalizations involve all three countries and, therefore, Pareto-improving trade liberalization agreements are all necessarily multilateral. To complete the rest of the proof, it suffices to show the existence of tariff reductions, $\epsilon^{1}, \epsilon^{2}, \epsilon^{3}$, such that

$$
\Delta \Pi_{(i+2) i}^{i}\left(\epsilon^{i+2}\right) \geq \Delta w_{i+1}^{i}\left(\epsilon^{i}\right), i=1,2,3
$$

with strict inequality for at least one country.

Note first that $\Delta w_{i+1}^{i}\left(\epsilon^{i}\right)$ and $\Delta \Pi_{(i+2) i}^{i}\left(\epsilon^{i+2}\right)$ are both continuous, monotonically increasing functions of $\epsilon^{i}$ and $\epsilon^{i+2}$, respectively. Furthermore, both terms are zero when $\epsilon^{i}=\epsilon^{i+2}=0$. Thus, by choosing $\epsilon^{1}$ to be sufficiently small, the Intermediate Value Theorem would imply that there are $\epsilon^{2}<t_{3}^{* 2}$ and $\epsilon^{3}<t_{1}^{* 3}$ such that

$$
\Delta \Pi_{(i+2) i}^{i}\left(\epsilon^{i+2}\right)=\Delta w_{i+1}^{i}\left(\epsilon^{i}\right), i=2,3 .
$$

Note also that by assumptions $A 1-A 2$,

$$
\frac{\partial\left[w_{i+1}^{i}+\Pi_{i(i+1)}^{i+1}\right]}{\partial t_{i+1}^{i}}=\frac{1}{9}\left[\left(1-2 \lambda_{i}\right) a_{i+2}^{i}-\left(5-\lambda_{i}\right) c_{i+1}^{i}+\left(4+\lambda_{i}\right)\left(c_{i+1}^{i+1}+t_{i+1}^{i}\right)-6 t_{i+1}^{i}\right]<0
$$

holds for $\lambda_{i} \geq 1$ and $t_{i+1}^{i}>0$. Thus, it follows that when $\epsilon^{i}$ is small enough, ${ }^{13}$

$$
\Delta \prod_{i(i+1)}^{i+1}\left(\epsilon^{i}\right)>\Delta w_{i+1}^{i}\left(\epsilon^{i}\right), \quad i=1,2,3 .
$$

\footnotetext{
${ }^{13}$ Our choice of $\epsilon^{2}$ depends on $\epsilon^{1}$ via functions $\Delta \Pi_{12}^{2}\left(\epsilon^{1}\right)$ and $\Delta w_{3}^{2}\left(\epsilon^{2}\right)$ together with the Intermediate Value Theorem. Since these functions are continuous and monotonically increasing and since they are both zero when $\epsilon^{1}=\epsilon^{2}=0, \epsilon^{2}$ is small whenever $\epsilon^{1}$ is small. Similarly, $\epsilon^{3}$ is small whenever $\epsilon^{2}$ is small. Hence, both $\epsilon^{2}$ and $\epsilon^{3}$ are small enough whenever $\epsilon^{1}$ is small enough.
} 
That is, the total net gain from country $i$ 's trade liberalization is positive. Together (9) and (10) imply $\Delta \Pi_{31}^{1}\left(\epsilon^{3}\right)>\Delta w_{1}^{3}\left(\epsilon^{3}\right), \Delta w_{1}^{3}\left(\epsilon^{3}\right)=\Delta \Pi_{23}^{3}\left(\epsilon^{2}\right)>\Delta w_{3}^{2}\left(\epsilon^{2}\right)$, and $\Delta_{3}^{2}\left(\epsilon^{2}\right)=$ $\Delta \Pi_{12}^{2}\left(\epsilon^{1}\right)>\Delta_{2}^{1}\left(\epsilon^{1}\right)$. This shows $\Delta \Pi_{31}^{1}\left(\epsilon^{3}\right)>\Delta w_{2}^{1}\left(\epsilon^{1}\right)$. We have therefore shown the existence of tariff reductions of all three countries that make country 1 better off without making countries 2 and 3 worse off. QED

The circular nature of the concessions as established in Proposition 2 implies that when a country, say country 1 , revokes its concession to country 2 , country 2 can do no better than to revoke its concession to country 3 in order to avoid double losses. This action inflicts no punishment upon country 1. This means that country 3's punishment, a third-party punishment, has to be in place in order to deter country 1 from defecting. The possibility of sustaining Pareto-improving trade liberalizations from the unilateral subgame-perfect equilibrium via third-party punishment is studied in the next section.

\section{Sustaining Multilateral Trade Liberalization via Third-Party Punishment}

As a direct implication of Proposition 2, country $i+1$ does not have any leverage to inflict damage upon country $i$ for defecting on any given Pareto-improving trade liberalization agreement. Thus, country $i+1$, the victim of country $i$ 's defection, must rely on country $i+2$ to carry out the needed punishment for deterring country $i$ from defecting on the given agreement. This confirms our early point that in circumstances where trading partners have to make circular concessions, the victimized partner may have to rely on a third-party to punish the defector in order to make the circular concessions self-enforcing.

When trade is infinitely repeated and punishment by third-parties is permissible, a trade liberalization agreement can be sustained by the following strategy of the trading 
countries, provided that the agreement is Pareto superior to the unilateral subgameperfect equilibrium and that future payoffs are not heavily discounted:

Stick to the agreement in the first period and continue to do so for as long as no country defects. If, however, one country defects by raising its tariffs, set the tariff as in the unilateral subgame-perfect equilibrium.

The above strategy is the trigger strategy which is commonly used in the standard proof of the classic folk theorem, according to which the strategies are self-enforcing (i.e. they form a subgame-perfect equilibrium of the corresponding infinitely repeated game) for large enough discount factors. The reader is referred to Gintis (2000, pp. 128-129) as an example. Note also that by reverting to their unilateral subgame-perfect equilibrium tariffs, one country provides a third-party punishment by forcing the defector to pay a higher tariff. In addition, as explained above, a Pareto improvement from the unilateral subgame-perfect equilibrium is not sustainable without third-party punishment. ${ }^{14}$ We have thus shown

Proposition 3: Suppose trade is infinitely repeated. Then, under the same conditions as in Proposition 1, every Pareto-improving trade liberalization agreement from the unilateral subgame-perfect equilibrium can be sustained via strategies that necessarily involve thirdparty punishment, provided that the discount factor is large enough for each country.

As shown by Proposition 2, circular concessions in terms of trade liberalizations (tariff reductions) are necessary for any Pareto improvement from the unilateral subgame-perfect

\footnotetext{
${ }^{14}$ Bendor and Mookherjee (1990) have shown that in a game with symmetric and separable payoff functions (which our model fits), any subgame-perfect equilibrium in which players play symmetric strategies can be sustained by a subgame-perfect equilibrium in which third-party sanction is not used; i.e., third-party sanction is of no use. Their result does not contrast our result because the players play asymmetric strategies in Proposition 3.
} 
equilibrium, small or large, so that country $i$ 's gain from country $i+2$ 's concession outweighs the loss of its own concession to country $i+1$, for $i=1,2,3$. Thus, in our setting, Proposition 3 implies that gains from trade are sustainable when and only when thirdparty punishment is permitted and the trading countries do not heavily discount their future payoffs.

\section{Conclusion}

We build a simple model with three countries to show that circular concessions may sometimes be the only way to achieve Pareto-improving trade liberalization. The circular nature of the concessions implies in particular that Pareto-improving trade liberalization must be multilateral. It also implies the necessity for third-party punishment in sustaining Pareto-improving trade liberalization agreements. An implication of the results here is that more explicit rules than those currently governing the settlement of disputes under WTO regarding third-party punishment may sometimes be needed.

The results of this paper are driven by some very specific assumptions. For example, the model is constructed in such a way that the resulting optimal tariffs are negative for two out of three goods in every country. Moreover, different countries impose positive tariffs on different goods. Relaxation of these assumptions will certainly affect our results. However, the basic spirit survives. What we have argued essentially is that in order to realize gains from trade, sometimes what we call "circular concessions" are required in which each country grants concession to one other country but in turn is (more than) compensated by a third country. This type of gain from trade will require third-party punishment for enforcement. Consequently, a multilateral trade relation can realize certain gains from trade that are not achievable through bilateral trade agreements. 
This idea of synergy creation through multilateral trade agreements does not depend on the assumptions discussed above. These assumptions are only used to greatly simplify our technical argument. Our argument is also different from the argument presented by Maggi (1999), which stresses the improvement of third-party sanctions in enforcing multilateral trade agreement. We are more concerned with the creation of surplus through circular concessions. Although different in spirit, we believe our insight to be a useful complementary argument in favor of multilateral trade relations. 


\section{References}

[1] Bagwell, Kyle and Staiger, Robert W. "A Theory of Managed Trade," American Economic Review, 1990, 84(4), 779-95.

[2] Bagwell, Kyle and Staiger, Robert W. "An Economic Theory of GATT," American Economic Review, 1999, 89(1), 215-248.

[3] Bhagwati, J. and Panagariya, A. "The Theory of Preferential Trade Agreements: Historical Evolution and Current Trends," American Economic Review Papers and Proceedings, 1996, 86(2), 82-87.

[4] Bendor, J. and D. Mookherjee (1990), "Norms, Third-Party Sanction, and Cooperation," Journal of Law, Economics and Organization, 6, 33-63.

[5] Deardorff, Alan V. and Stern, Robert M., "Multilateral Trade Negotiations and Preferential Trading Agreements," In Analytical and Negotiating Issues in the Global Trading System, edited by A.V. Deardorff and R.S. Stern, 1997, Ann Arbor: The University of Michigan Press.

[6] Gintis, Herbert. Game Theory Evolving: A Problem-Centered Introduction to Modeling Strategic Behavior. Princeton University Press, 2000.

[7] Johnson, Harry G., "Optimal Tariffs and Retaliation," Review of Economic Studies, 1953-54, 21, 142-53.

[8] Krugman, Paul R. and Obstfeld, Maurice. International Economics: Theory and Policy. Addison-Wesley, Fifth Edition, 2000.

[9] Maggi, Giovanni, "The Role of Multilateral Institutions in International Trade Cooperation," American Economic Review, 1999, 89(1), 190-214.

[10] Staiger, Robert. "International Rules and Institutions for Trade Policy," Chapter 29, in Handbook of International Economics, Volume III, edited by Gene M. Grossman and Kenneth Rogoff, 1995, North-Holland 


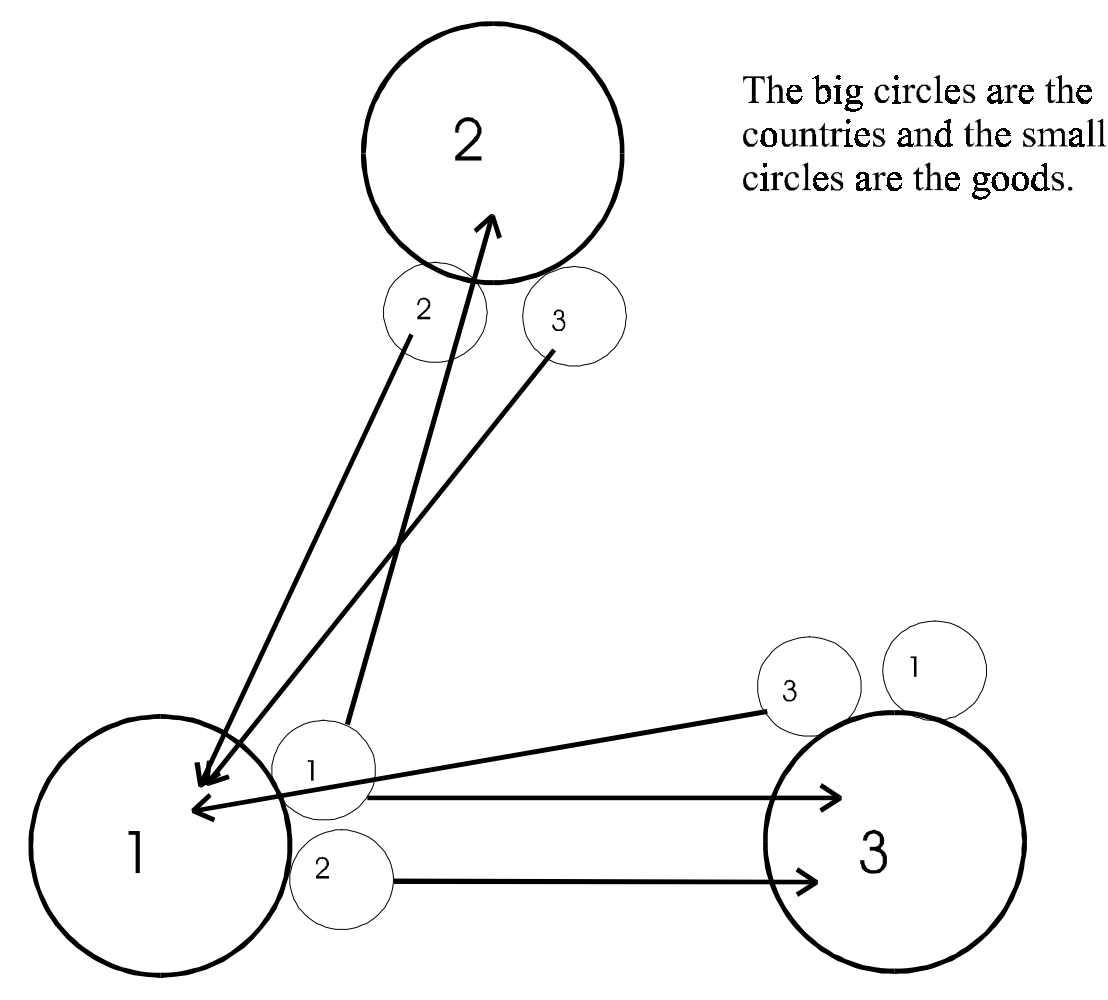

Figure 1: The Pattern of Trade

Figure 1: 